among the most significant advances in the medical treatment of these conditions in the history of medicine. These facts must be weighed against the extremely rare instances of these relatively minor epidermal reactions. Rashes are not infrequent in hypertensive patients taking methyldopa, while 1 in 5 patients treated with the latter develop a positive Coombs test and 1 in $\mathbf{5 0 0}$ go on to develop haemolytic anaemia. ${ }^{5}$ Such features have occasioned less comment than the development of this rare and usually reversible oculocutaneous syndrome in patients on treatment with beta-blocking drugs.

We are appreciative of the professional advice offered in this case by Mr B Martin.

${ }^{1}$ Felix, R H, Ive, F A, and Dahl, M G C, British Medical fournal, 1975, 1, 626.

2 Wright, P, British Medical fournal, 1975, 1, 595.

3 Holt, P J A, and Waddington, E, British Medical fournal, 1975, 2, 539.

4 Assem, E S K, British fournal of Pharmacology, 1975, 54, 184.

5 Worlledge, S M, Carstairs, K C, and Dacie, J V, Lancet, 1966, 2, 135.

Departments of Surgery (Ophthalmology) and Medicine (Cardiovascular Unit), University of Leeds, General Infirmary, Leeds LS1 3EX

R BEVIS CUBEY, FRCS, DO, tutor in ophthalmology

S H TAYLOR, BSC, FRCP, consultant physician and senior lecturer in medicine

\section{Ischaemic necrosis of lesser curve after proximal gastric vagotomy}

Avascular necrosis of the lesser curve of the stomach is a potentially fatal complication of proximal gastric vagotomy. ${ }^{1-5}$ After an uneventful operation the patient usually shows some evidence of delayed gastric emptying or of "ileus." On the third to sixth postoperative day collapse occurs due to peritonitis from a free perforation of the stomach. In patients who have survived this disaster the perforation was closed soon after its development. ${ }^{15}$ We report here a different presentation of this dangerous complication.

\section{Case report}

A 50-year-old hypertensive man progressed normally after an uneventful proximal gastric vagotomy for chronic duodenal ulceration until the fourth postoperative day, when he had a hypotensive episode. The next day he collapsed and passed a large melaena stool. A haemoglobin level of $7.4 \mathrm{~g} / \mathrm{dl}(7.4 \mathrm{~g} / 100 \mathrm{ml})$ suggested that part of the bleeding had occurred the previous day. Treatment with 6 units of blood over 24 hours restored the central venous pressure to normal and the haemoglobin to $10 \mathrm{~g} / \mathrm{dl}$. Two days' later however, a further haematemesis occurred, so the abdomen was immediately reopened. The stomach and entire small bowel were distended with blood. A congested area high on the lesser curve of the stomach developed at a touch into a free perforation of the stomach out of which blood clots extruded. It seemed logical to complete the disruption of the lesser curve, and this was done easily with the side of the finger to reveal a large oval ulcer $(6 \times 2 \mathrm{~cm})$ on the lesser curve in the middle of which a small artery was bleeding fiercely. In contrast, the stomach mucosa was purple except in the fundus where it was a norma pink colour. A high partial gastrectomy was performed without using clamps (but with very little bleeding) by cutting the stomach at the junction of viable and ischaemic micosa. The patient made a good recovery and 5 months later was well apart from a limited appetite and a dumping tendency.

\section{Discussion}

Halvorsen et $a l^{3}$ noted that the lesser curve of the stomach is a potentially ischaemic area, the implication being that sloughing of the lesser curve is a specific hazard of proximal gastric vagotomy. In our case the slough was plugged by lesser omentum. An eroded artery in the omentum became the source of bleeding. Surgeons who adopted proximal gastric vagotomy for uncomplicated duodenal ulceration believed it to be free from both serious and minor complications. Unfortunately, this view must be qualified. In
Johnston's survey ${ }^{4}$ sloughing of the lesser curve occurred in 7 out of 4857 operations, an incidence of recognised cases of 1.4 per $10^{3}$. Assuming that the occurrence of sloughing follows a binominal distribution $99 \%$ confidence limits for the true incidence would be 3.6 per $10^{5}$ operations at the lowest, and 2.8 per $10^{3}$ operations at the greatest. If the incidence should prove to be $2-3$ per $10^{3}$ operations the complication will have to be taken seriously. Our case shows that sloughing of the lesser curve of the stomach may present as haemorrhage as well as perforation.

1 Wyllie, J H, British Medical fournal, 1974, 2, 561.

2 Hall, R, Summers, G A C, and Green, M A, British Medical fournal, $1974,3,806$.

3 Halvorsen, J F, et al, British Medical fournal, 1975, 2, 590.

4 Johnston, D, British fournal of Surgery, 1975, 62, 160.

5 Brodie, S W, British Medical fournal, 1975, 3, 229.

Surgical Unit, University College Hospital Medical School, London WC1E 6JJ

FIONNA P MOORE, MB, BS, house surgeon

J H WYLLIE, MD, FRCS, reader in surgery

\section{Minimising blood loss in caesarean section}

For surgeons working in hospitals patronized by the first among the martyrs of childbirth in India-the rural wife-emergency caesarean section on an exhausted, shocked, and exsanguinated woman is a common task, with or without the complication of rupture of the gravid uterus. Of the latter, one was seen every other day in the first 10 days of 1975-and three on the 10th. Blood is not always available for transfusion and is always expensive (50 rupees, $£ 3$, or $\$ 5$ per $330 \mathrm{ml}$ ), so that the prevention of undue bleeding is simply lifesaving.

\section{Method}

As soon as the child is born (or in accidental or unavoidable antepartum haemorrhage, fetal death, or rupture of the uterus before delivery) a straight intestinal clamp, six inches $(15 \mathrm{~cm})$ long with longitudinal or diagonal striations of the blades, is applied along each side of the uterus. The clamp encloses the whole length of the broad ligaments, including the infundibulopelvic ligaments, and cuts off, gently and temporarily, the entire blood supply of the viscus. It is then possible to open and close the uterus. Also an inspection to decide whether to repair or remove the uterus can be made more easily. If the clamps are applied before delivering a live child, speed will offset the effect of suppressing the placental circulation. After closing the uterine wall and before stitching the peritoneal flap the release of the intestinal clamps will show any inefficient haemostasis, and allow the venous engorgement of the broad ligament.

It is, of course, necessary to make an incision that is longer than usual and it should be midline and subumbilical to allow the clamps to be applied on the unemptied uterus. This will make the manoeuvre unacceptable where the bare abdomen, free of blemish or bulge, is popularly displayed. In those cases the transverse, suprapubic incision is imperative. But in India unsightly abdominal striae and wide separation of the recti are universal in the parous. A transverse scar is not appreciated because the hair of the mons veneris, which should mark it, is usually plucked or close shaved, and the vertical scar blends into the linea nigra.

\section{Comment}

My method is, recognizably, inspired by Victor Bonney, who used to advise occlusion of the uterine vessels by sponge forceps during extended myomectomy. Should it become popular, a modification by shortening the shanks of the intestinal clamps would make the instruments more handy.

Nazareth Hospital, Mokameh, Bihar, India

MEAVE KENNY, MD, FRCOG, obstetrician-in-charge 